\title{
Investigation of The Workable Days in Agriculture Using Meteorological Parameters
}

\author{
Savaş Kuşcu',a,*, Ufuk Türker ${ }^{1, b}$, Burak Şen $^{2, c}$ \\ ${ }^{1}$ Agricultural Machinery and Technologies Engineering Department, Faculty of Agricultural, Ankara University, 61110 Ankara, Turkey \\ ${ }^{2}$ Biosystems Engineering Department, Faculty of Agricultural Sciences and Technologies, Niğde Ömer Halisdemir University, 51240 Niğde, Turkey \\ *Corresponding author

\begin{tabular}{l|l}
\hline A R T I C L E I N F O & A B S T R A C T \\
\hline Research Article & $\begin{array}{l}\text { In this study, it was aimed to determine the workable days in agriculture using meteorological } \\
\text { parameters, and a databank was formed obtaining the inputs from all weather stations in Central } \\
\text { Anatolia Region, which cover a 20-year period, from 1986 to 2006. Running mathematical model } \\
\text { in a computer software specifically designed for this purpose, the data of this databank were } \\
\text { exploited to calculate the workable days on a land for soil treatment, crop care and harvest for any } \\
\text { given region and to show these data with graphs on monthly or yearly basis. This software may help } \\
\text { to use time more economically and reduce the system costs directly or indirectly. Moreover, the data } \\
\text { collected are quite necessary to prepare some national or local charts and graphs related to the general } \\
\text { distribution of various climate factors. }\end{array}$
\end{tabular}

Keywords:

Agricultural Meteorology

Climate

Harvesting Period

Productivity

Workable Days

Türk Tarım - Gıda Bilim ve Teknoloji Dergisi 7(11): 1960-1965, 2019

\section{Tarımda Çalışılabilir Gün Sayılarının Meteorolojik Parametrelerle Hesaplanması}

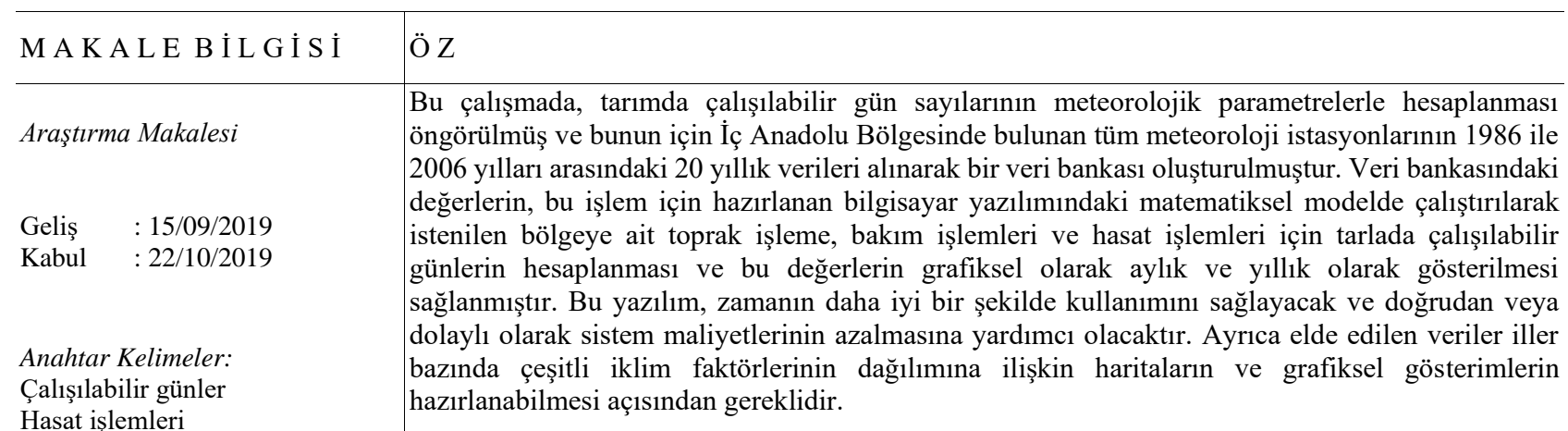

Hasat işlemleri

İklim

Verimlilik

Zirai meteoroloji 


\section{Giriş}

Günümüzde ekonominin temel amacı, sınırlı bulunan üretim faktörlerinden maksimum derecede faydalanmaktır. Tarımsal işletmelerde, mevcut şartlarda en yüksek gelirin elde edilebilmesi ve değişen ekonomik şartlara uyum sağlanabilmesi için tarımsal üretim planlaması büyük önem taşımaktadır. Üretim planlaması yapılabilmesi ve başarılı sonuçların elde edilebilmesi için her şeyden önce sağlıklı verilerin temin edilmesine ihtiyaç vardır.

Tarımsal İşletmelerde üretimi sınırlayan en önemli üretim faktörlerinden birisi de işgücüdür. $\mathrm{Bu}$ nedenle, tarımda işgücü kapasitesinin etkin bir şekilde değerlendirilmesi ve işgücü planlaması açısından tarla çalışma günlerinin doğru olarak tespit edilmesi yararlı olacaktır. Bazı tarla işleri yılın ancak belirli günlerinde yapılabilmektedir. Bu sebeple bir yıllık tarımsal üretim dönemi, iş yükünün en yoğun olduğu dönemleri dikkate alabilmek amacıyla birkaç çalışma dönemine bölünebilir. Böylece üretim faaliyetlerinin genişlemesi, her bir çalışma dönemindeki mevcut tarla çalışma günlerinin izin verdiği ölçüde olabilir. Tarla çalışma günleri denilince, bir çalışma döneminde, iklim şartlarının işletme avlusu dışında yapılacak işlerin yapılmasına olanak sağladığ 1 iş günleri anlaşılmaktadır. Bir İşletmenin mevcut şartlarda mümkün olan en yüksek geliri elde edebilmesi için iyi bir planlama çalışması ne kadar önemli ise, bu planlama çalışmasında tarla çalışma günlerinin tespiti de o kadar gerekli olmaktadir.

Ülkemizde bugüne kadar tarla çalışma günlerinin tespiti üzerine yapılan çalışmalar genellikle planlamaya yönelik çalışmalar olup, bu çalışmalar daha çok belirli bir bölge ve/veya alanda gerçekleştirilmiştir. Ayrıca Türkiye coğrafi konumu ve fiziki özellikleri sebebiyle yağış, evapotranspirasyon, sicaklık, güneşlenme, radyasyon vb. iklimsel parametreler açısından çok geniş bir dağılım göstermektedir (Selek ve Aksu, 2020). Diğer bir ifade ile konuyla ilgili daha önce yapılan çalışmalar, genellikle mikro amaçlı, sadece bir il veya sadece bir bölge için yapılan çalışmalardır. $\mathrm{Bu}$ çalışmada, Türkiye'nin İç Anadolu Bölgesindeki iller seçilerek, bu illerde tüm bölgenin genel ürün desenini yansıtabilen hakim ürünler için tarla çalışılabilir günlerinin tespit edilmesi amaçlanmıştır.

Çalışılabilir gün sayıları veya oranları değişik yöntemlerle tahmin edilebilmektedir. Özellikle ABD vb. gibi gelişmiş ülkelerde uygun tarla çalışma günlerinin belirlenmesine yönelik değişik çalışmalar yapılmış ve sadece bu amaca yönelik olarak, çalışılabilir tarla günleri gözlem kayıtlarının tutulduğu özel kayıt istasyonları kurulmuştur. $\mathrm{Bu}$ istasyonlara ait çok yıllık kayıtlar kullanılarak, çalışılabilir tarla günlerine ilişkin değerler kolaylıkla elde edilebilmektedir. Bu tür kayıtların eksik olduğu gelişmekte olan ülkelerde de tarım makineleri ile çalışmaya uygun çalışılabilir tarla günlerine ilişkin tahminler, çok yıllık meteorolojik kayıtları kullanan bilgisayar programları ile, kabul edilebilir bir doğrulukla tahmin edilebilmektedir (Fulton ve ark., 1976; Williams, 1980; Parsons ve Doster, 1982; Hetz ve ark., 1983; Işık ve Sabanc1, 1989; Işık ve Toros, 1992).

Türkiye de pek çok araştırmacı farklı bölgelerde işgücü kapasitesinin hesaplanmasında kullanılmak üzere toplam çalışma periyodunu, bölge koşullarında ana kültür bitkisinin vegetatif gelişmelerini göz önünde bulundurarak, ana dönemlere ve/veya alt dönemlere ayırmıștır (Erkuş, 1976; Demirci, 1978; 1980; Çetin, 1987; Tatlidil, 1987; 1992; Serin, 1989; Özçelik, 1985; 1993; Cinemre, 1990; Fidan, 1996; Kılıç, 1997; Ceyhan, 1998; Dellal, 2000).

Tarım makinaları ile çalışmada uygun tarla çalışma günlerinin tahminine yönelik yerli ve yabancı kaynaklı 'çalışmaların çoğunluğunda, model çözümleri çok yıllık iklim verileri ve bazı toprak özellikleri kullanılarak yapılmıştır (Jones ve ark., 1972; Tulu ve ark., 1974; İnan 1977; Bölükoglu, 1982; Rosenberg ve ark., 1982; Hetz ve ark., 1983; Arın ve Kayışoğlu, 1985; Güzel ve Haktanır, 1986; Von Bargen ve ark., 1986; Sindır ve Evcim, 1992; Toros ve Işık, 1994).

Elliot ve ark. (1977), toprak işleme işlemleri için çalışabilir günlerin tahmininde, iki farklı toprak tipi, üç farklı yüzey örtüsü oranı ve beş farklı drenaj koşulunu dikkate alan bir "toprak nemi denge modelini" kullanmışlardır. Modelin sonuçları Illinois ürün Kayıtları Servisi tarafından yapılan tarla çalışma günleri gözlemleri verileriyle karşılaştırılmış ve bir aylık esasla, toprak işleme işleri için çalışılabilir günlerin tahmininde modelin doğruluğu yeterli bulunmuştur. Model sonuçları ile gerçek kayıtların \%84 oranında uyuştuğu belirlenmiştir.

Diğer gelişmekte olan ülkelerde olduğu gibi, ülkemizde de çalışılabilir tarla günleri ile ilgili olarak tutulmuş özel kayitlar yoktur. $\mathrm{Bu}$ nedenle çok yıllık meteorolojik kayıtları kullanarak, çalışılabilir gün oranları veya sayılarını hesaplayan üniversal özellikte bir modelin geliştirilebilmesi ve sonuçların bilgisayardan kısa sürede alınabilmesi ülkemiz açısından büyük önem taşımaktadır.

Yukarda belirtilen yöntemlerin dışında Kıral (1998), “Türkiye'de Tarımsal işgücü Arzı” isimli çalışmasında, üretim periyodunu çalışma dönemlerine ayırmamış, tarımsal işgücü arzını iller, bölgeler ve Türkiye ölçeğinde aylar itibariyle hesaplamıştır. Buna göre, her ay için dini, milli bayram günleri ile haftalık tatil günlerinin sayılarını çıkarmış ve genel çalışma günlerini bulmuştur. Genel çalışma günlerinin sayısından da karla kaplı ve donlu günler ile yağış nedeniyle çalışılamayan gün sayılarını çıkarmak suretiyle tarla çalışma günlerini her ay için ayrı ayrı hesaplamıştır. Ayrıca Vatandaş (1987), Ankara koşullarında yaptığı çalışmasında, makine iş saati kısıtı yönünden, dönemlerdeki net çalışılabilir gün sayılarının hesaplanmasında kullanılmak üzere, makine iş saati yönünden yoğun olan üç dönem belirlemiş ve tarla çalışma günlerini ondalıklı olarak hesaplamıştır.

Herhangi bir yöntemle, bir yöre veya işletmeye ait çok yıllık iklim ve bazı toprak özellikleri kullanılarak yıl boyunca belirli periyotlarda tahmin edilen çalışılabilir gün sayıları veya oranlarının, o yöre veya işletmeye ait gerçek kayıtlarla karşılaştırılarak kullanılan modelin geçerlilik testinin yapılması, yani kullanılan modelin güvenilirliğinin belirlenmesi de modelin geliştirilmesi kadar önemlidir.

Geçerlilik testinin yapılabilmesi için, işletme veya yöre koşullarında tarım makinaları ile tarlada çalışılabilen günlere ilişkin kayıtların tüm yıl veya yıllar boyunca tutularak, ele alınan periyotlarda model çözümleriyle karşılaştırmaları gerekir. Bu tür çalışmalar ülkemizde son yıllarda önem kazanmaya başlamış olup henüz bu yönde tutulmuş herhangi bir gözlem kaydı bulunmamaktadır. 


\section{Materyal ve Yöntem}

\section{Materyal}

Bu çalışmanın ana verilerini, Türkiye'deki tüm iller ve havzalarda bulunan meteorolojik istasyonlarından 19872006 yıllarına ait Meteoroloji Genel Müdürlüğü Araştırma ve Bilgi İşlem Daire Başkanlığı'ndan temin edilen ortalama sıcaklık, toprak sıcaklık ve günlük yağış değerleri oluşturmaktadır. Bu istasyonlarda, istasyonların tipine göre değişmekle birlikte, çok sayıda iklim elemanının rasadı yapılmaktadır. Bunların tamamının alınması çalışmanın boyutunu çok fazla artıracağından bu çalışmada aşağıdaki iklim elemanları dikkate alınmıştır:

Toprak sıcaklığl (günlük ortalama); Meteoroloji Genel Müdürlüğü veri bankasında $5,10,20,50$ ve $100 \mathrm{~cm}$ derinlikteki toprak sıcaklıkları mevcut olup, çalışmada 10 cm derinlikteki toprak sıcaklık ortalaması kullanılmıştır. Ortalama; 07, 14 ve 21 saatlerindeki rasatlar ortalamasından elde edilmektedir.

Ortalama sıcaklık (günlük ortalama); Meteoroloji Genel Müdürlüğü veri bankasındaki 07,14 ve 21 saatlerindeki sıcaklık değerlerinin ortalaması kullanılmıştır.

Yağış (günlük ortalama); Çalışma alanının sınırları İç Anadolu Bölgesi olarak belirlenmiştir. Bu alana ait iller: Aksaray, Ankara, Çankırı, Çorum, Eskişehir, Karaman, Kayseri, Kırıkkale, Kırşehir, Konya, Nevşehir, Niğde, Sivas ve Yozgat'tır.

\section{Metot}

Tarlada çalışılabilir gün sayısının belirlenmesi amacıyla bir matematiksel model geliştirilmiş ve bu modele ait bilgisayar yazılımı gerçekleştirilmiştir. Meteorolojik veriler Microsoft Access veri tabanına yüklenmiştir. $\mathrm{Bu}$ verileri kullanarak tarlada çalışılabilir gün sayısının hesaplanması ve bu verilerin grafik analizini yapabilmek için de Delphi programlama editöründe yeni bir yazılım geliştirilmiştir.

\section{Çalışılabilir Gün Sayısı}

Genel bir ifade ile "çalışılabilir gün" herhangi bir tarım makinesinin kendisinden beklenen işlevi gerçekleştirebildiği, yani toprakta çalışabildiği gün olarak tanımlanabilir. Çalışılabilir tarla günlerinin belirli bir periyottaki toplam sayısına "çalışılabilir gün sayısı" bu günlerin periyot uzunluğuna oranlanmasıyla elde edilen orana da "çalışılabilir gün oranı" adı verilmektedir. Bunlardan herhangi birisinin bilinmesi durumunda diğeri de hesaplanabilecektir. (Iş1k ve Toros, 1992),

Çalışılabilir gün sayısının hesaplanabilmesi için öncelikle çalışılabilirlik kriterlerinin saptanması gerekir. Bu çalışmada çalışılabilirlik kriterleri, DARGA (1989)'dan alınmıştır. Tarlada çalışılabilir gün sayısı hesaplanmasındaki işlemler özelliklerine göre üç gruba ayrılmış ve her grup için farklı kriterler saptanmıştır. İşlem grupları ve her grup için belirlenen kriterler şöyledir:

$$
\begin{aligned}
& \text { I. Grup Işslemler (Toprak Işsleme Işslemleri) } \\
& \mathrm{Bu} \text { işlemlerin yapılabilmesi için; } \\
& \text { SORT }_{i} \\
& \text { YAĞ }_{i} \\
& \text { YAĞi + YAĞi-1 } \\
& >5^{\circ} \mathrm{C} \\
& <2,5 \mathrm{~mm} \\
& <3,5 \mathrm{~mm} \\
& \mathrm{TSIC}_{\mathrm{i}}
\end{aligned}
$$

II. Grup Işlemler (Bakım Işslemleri)

$\begin{array}{ll}\text { SORT }_{i} & >5^{\circ} \mathrm{C} \\ \text { YAĞ }_{i} & <0,5 \mathrm{~mm} \\ \text { TSIC }_{i} & >5^{\circ} \mathrm{C} \text { olmalıdır. }\end{array}$

III. Sınıf İşlemler (Hasat İşlemleri)

$\mathrm{Bu}$ işlemlerin yapılabilmesi için;

$\mathrm{SORT}_{\mathrm{i}}$

YAĞ $_{\mathrm{i}}$

$>15^{\circ} \mathrm{C}$

YAĞi-1

$<0,0 \mathrm{~mm}$

$<2,0 \mathrm{~mm}$ olmalidir.

Burada;

SORT $_{\mathrm{i}}$ i gününde ortalama sıcaklık $\left({ }^{\circ} \mathrm{C}\right)$

$\mathrm{YAG}_{i} \quad$ i Günündeki yağış miktarı $(\mathrm{mm})$

YAĞi-1 i gününden önceki günün yağış miktarı (mm)

YAĞi-2 i gününden iki önceki günün yağış miktarı (mm)

$\mathrm{TSIC}_{\mathrm{i}} \quad$ i günüde $10 \mathrm{~cm}$ 'deki toprak sıcaklığ $1\left({ }^{\circ} \mathrm{C}\right)$ dir.

Çalışılabilir gün sayısının daha kısa zamanda ve kolaylıkla hesaplanması için Delphi programıla "GÜNSAY" isimli grafiksel arayüze sahip kullanıcı dostu uzman bir program geliştirilmiştir. Programa ait bazı veri giriş, seçim ve analiz sonucu görüntüleri Resim1, Resim2, Resim3 de verilmiştir.

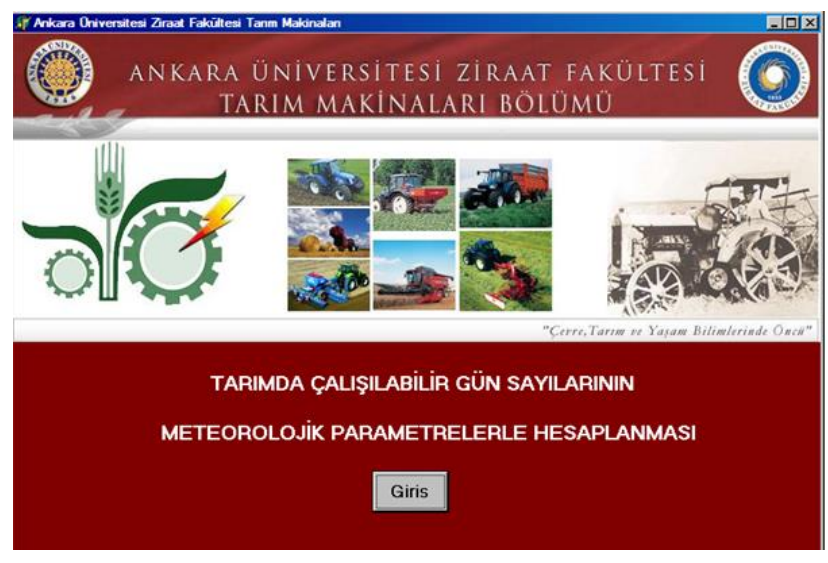

Resim1 Programın giriş sayfası Image 1 Start page of software

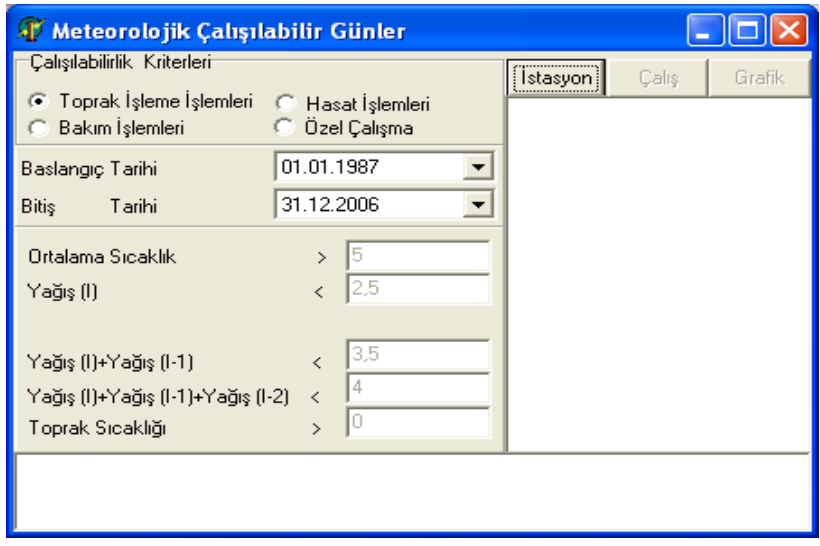

Resim 2 Programda çalışılabilirlik kriterlerinin belirlendiği arayüz

Image 2 Interface in which the software's workability criteria are determined 


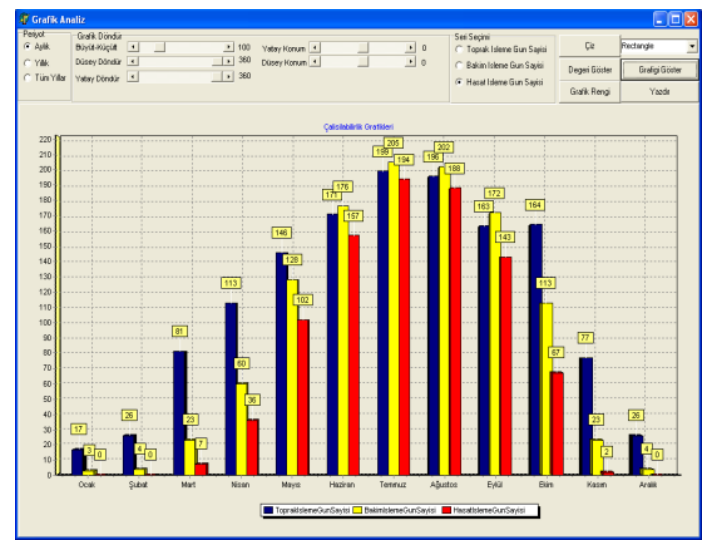

Resim 3 İstenilen değerlerin analiz sonuçlarının toplu olarak gösterimi

Image 3 Collective display of analysis results of desired

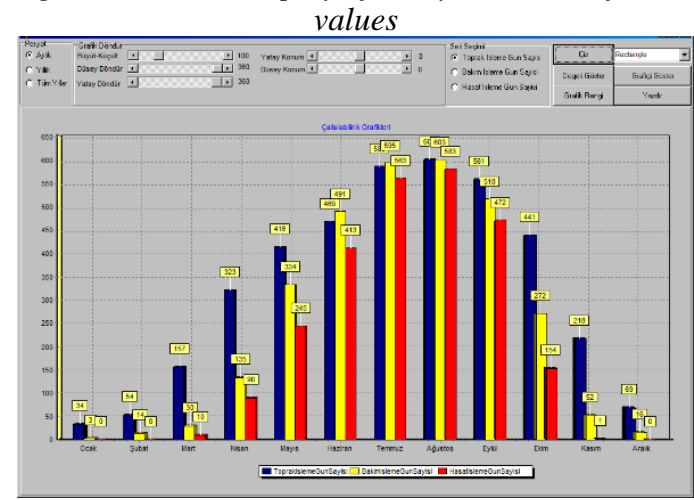

Resim 4 Niğde ilinin 1987-2006 yılları arasındaki aylık veri grafiği

Image 4 Monthly data graph of Niğde province between 1987-2006

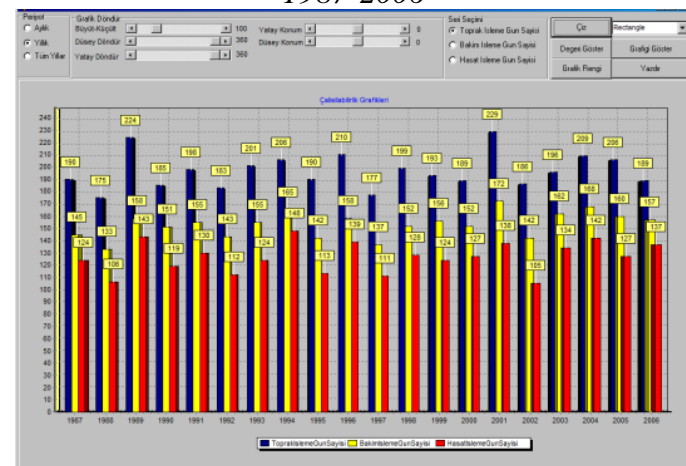

Resim 5 Niğde ilinin 1987-2006 yılları arasındaki yıllık veri grafiği

Image 5 Yearly data graph of Niğde province between 1987.

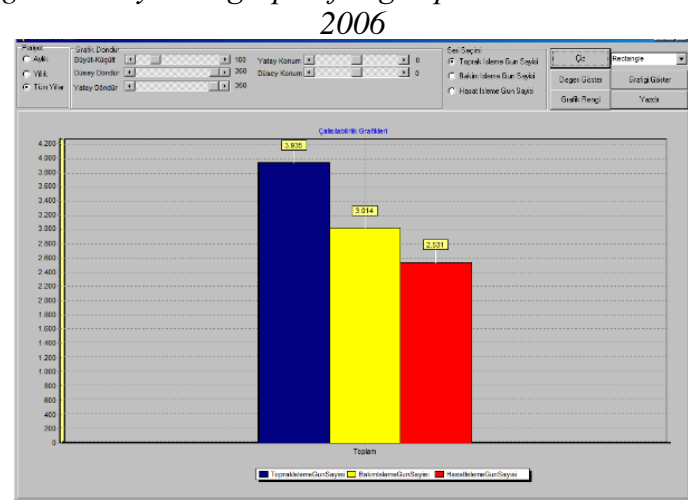

Resim 6 Niğde ilinin 1987-2006 yılları arasındaki toplam y1llık veri grafiği

Image 6 Total annual data graph of Niğde province between 1987-2006

\section{Bulgular ve Tartışma}

Çalışma sonunda İç Anadolu Bölgesine ait illerin 19872006 yılları arasındaki toprak işleme, bakım işlemleri ve hasat işlemleri için üç grup halinde aylık, y1llık ve toplam sürelerde tarlada çalışılabilir gün sayılarının değerleri belirlenmiştir. Belirlenen değerler görsel ve sayısal olarak programdan çıktı olarak alınmıştır. Örnek olarak Niğde ilinin 1987-2006 yılları arasındaki aylık veri grafiği, Niğde ilinin 1987-2006 yılları arasındaki yıllık veri grafiği, Niğde ilinin 1987-2006 yılları arasındaki toplam yıllık veri grafiği Resim 4, Resim 5 ve Resim 6 da verilmiştir.

\section{Iç Anadolu Bölgesine Ait Çalışılabilir Gün Sayı} Değerleri

Hazırlanan GÜNSAY programı kullanılarak Aksaray, Ankara, Çankırı, Çorum, Eskişehir, Karaman, Kayseri, Kırıkkale, Kırşehir, Konya, Nevşehir, Niğde, Sivas ve Yozgat illeri için toprak işleme işlemleri için çalışılabilir gün sayısı, bakım işlemeleri için çalışılabilir gün sayısı, hasat işlemeleri işlemleri için çalışılabilir gün sayısı değerleri hesaplanmıştır (Çizelge 1).

Analiz sonuçlarına göre toprak işleme işlemleri için çalışılabilir gün sayısı 1987-2006 yılları arasındaki oranlar, Aksaray için \%52,1; Ankara için \%52,31; Çankırı için \%45,9; Çorum için \%43,43; Eskişehir için \%36,02; Karaman için \%53,43; Kayseri için \%43,47; Kırıkkale için \%52,02; Kırşehir için \%51,58; Konya için \%52,87; Nevşehir için \%53,10; Niğde için \%53,90; Sivas için \%44,96; Yozgat için \%45,17 olarak bulunmuştur.

Bakım işlemeleri için çalışılabilir gün sayısı 1987-2006 yılları arasındaki oranlar, Aksaray için \%37,23; Ankara için \%41,23; Çankırı için \%33,98; Çorum için \%28,49; Eskişehir için \%23,42; Karaman için \%36,91; Kayseri için \%28,50; Kırıkkale için \%40,93; Kırşehir için \%40,06; Konya için \%38,83; Nevşehir için \%36,63; Niğde için $\% 41,28$; Sivas için \%32,68; Yozgat için \%34,50 olarak bulunmuştur.

Hasat işlemeleri işlemleri için çalışılabilir gün sayısı 1987-2006 yılları arasındaki oranlar; Aksaray için \%37,60; Ankara için \%33,60; Çankırı için \%30,16; Çorum için \%28,58; Eskişehir için \%25,01; Karaman için \%38,16; Kayseri için \%32,61; Kırıkkale için \%35,06; Kırşehir için \%33,89; Konya için \%35,05; Nevşehir için \%31,84; Niğde için \%34,67; Sivas için \%28,45; Yozgat için \%27,09 olarak bulunmuştur.

Ayrıca hazırlanan GÜNSAY programı kullanılarak İç Anadolu Bölgesi'ndeki iller için 5 er yıllık periyodlarda toprak işleme işlemleri için çalışılabilir gün sayısı oranları, bakım işlemeleri için çalışılabilir gün sayısı oranları, hasat işlemleri için çalışılabilir gün sayısı oranları hesaplanmıştır (Çizelge 2).

Herhangi bir tarımsal yörede, tarım makineleri ile çalışmaya uygun tarla günlerinin bilinmesi; o yörede bulunan tarım işletmelerinde doğru iş planlarının gerçekleştirilmesi ve işletme özelliklerine uygun tarım makinesi kapasitelerinin seçiminde önemli bir faktördür. İşletmelerde uygun iş planlarının yapılması ve doğru mekanizasyon yatırımlarının oluşturulması ile hem işletmenin yıllık kazancı artırılacak hem de ülke kaynaklarının doğru kullanılması sağlanmış olacaktır. 
Çizelge 1 İl kodları, iller ve toprak işleme işlemleri

Table 1 Provincial codes, provinces and tillage operations

\begin{tabular}{c|lccc}
\hline $\begin{array}{c}\text { İstasyon } \\
\text { Numarası }\end{array}$ & \multicolumn{1}{c}{$\begin{array}{c}\text { İl } \\
\text { Adı }\end{array}$} & $\begin{array}{c}\text { Toprak İşleme } \\
\text { Gün Sayıs1 }\end{array}$ & $\begin{array}{c}\text { Bakım İşlemleri } \\
\text { Gün Sayıs }\end{array}$ & $\begin{array}{c}\text { Çalış1labilir } \\
\text { Gün Sayıs Değerleri }\end{array}$ \\
\hline 17192 & Aksaray & 3862 & 2718 & 2745 \\
17130 & Ankara & 3819 & 3010 & 2453 \\
17080 & Çankırı & 3351 & 2481 & 2202 \\
17084 & Çorum & 3171 & 2080 & 2087 \\
17123 & Eskişehir & 2672 & 1710 & 1826 \\
17246 & Karaman & 3901 & 2695 & 2786 \\
17196 & Kayseri & 3174 & 2081 & 2381 \\
17135 & Kırkkale & 3803 & 2988 & 2560 \\
17160 & Kirşehir & 3766 & 2925 & 2474 \\
17244 & Konya & 3860 & 2835 & 2559 \\
17193 & Nevşehir & 3877 & 2674 & 2325 \\
17250 & Niğde & 3935 & 3014 & 2531 \\
17090 & Sivas & 3284 & 2386 & 2077 \\
17140 & Yozgat & 3298 & 2519 & 1978 \\
\hline
\end{tabular}

Çizelge 2 Toprak işleme işlemleri için çalışılabilir gün sayısı oranları, bakım işlemeleri için çalışılabilir gün sayısı oranları, hasat işlemeleri işlemleri için çalışılabilir gün sayısı oranları tablosu

Table 2 Table of workable rates for tillage operations, table of workable rates for maintenance operations, table of workable rates for harvest operations

\begin{tabular}{|c|c|c|c|c|c|c|}
\hline \multirow{3}{*}{ İl Ad 1} & \multicolumn{2}{|c|}{$\begin{array}{c}\text { Toprak İşleme } \\
\text { Gün Sayısı Oranı }\end{array}$} & \multicolumn{2}{|c|}{$\begin{array}{l}\text { Bakım İşlemleri } \\
\text { Gün Sayısı Oranı }\end{array}$} & \multicolumn{2}{|c|}{$\begin{array}{c}\text { Çalışılabilir } \\
\text { Gün Sayısı Oranı }\end{array}$} \\
\hline & \multicolumn{2}{|c|}{ Dönemler } & \multicolumn{2}{|c|}{ Dönemler } & \multicolumn{2}{|c|}{ Dönemler } \\
\hline & 1997-2002 & $2002-2006$ & $1997-2002$ & $2002-2007$ & 1997-2002 & $2002-2007$ \\
\hline Aksaray & $\% 54,73$ & $\% 54,95$ & $\% 38,73$ & $\% 41,20$ & $\% 38,13$ & $\% 37,69$ \\
\hline Ankara & $\% 50,35$ & $\% 54,73$ & $\% 40,05$ & $\% 43,12$ & $\% 33,53$ & $\% 34,73$ \\
\hline Çankırı & $\% 43,19$ & $\% 47,61$ & $\% 33,80$ & $\% 35,56$ & $\% 29,91$ & $\% 31,50$ \\
\hline Çorum & $\% 42,30$ & $\% 44,65$ & $\% 29,47$ & $\% 28,27$ & $\% 28,98$ & $\% 28,65$ \\
\hline Eskişehir & $\% 44,00$ & $\% 45,47$ & $\% 29,31$ & $\% 30,24$ & $\% 31,06$ & $\% 31,01$ \\
\hline Karaman & $\% 54,02$ & $\% 54,84$ & $\% 38,84$ & $\% 37,75$ & $\% 38,73$ & $\% 37,91$ \\
\hline Kayseri & $\% 43,89$ & $\% 45,58$ & $\% 28,60$ & $\% 29,80$ & $\% 33,04$ & $\% 33,31$ \\
\hline Kirıkkale & $\% 51,89$ & $\% 54,95$ & $\% 41,20$ & $\% 41,91$ & $\% 35,45$ & $\% 36,10$ \\
\hline Kırşehir & $\% 50,35$ & $\% 53,58$ & $\% 38,57$ & $\% 42,30$ & $\% 33,31$ & $\% 34,35$ \\
\hline Konya & $\% 53,47$ & $\% 54,04$ & $\% 39,89$ & $\% 40,10$ & $\% 35,01$ & $\% 35,23$ \\
\hline Nevşehir & $\% 55,01$ & $\% 54,63$ & $\% 37,47$ & $\% 38,30$ & $\% 32,38$ & $\% 32,38$ \\
\hline Niğde & $\% 54,08$ & $\% 54,02$ & $\% 41,58$ & $\% 42,42$ & $\% 34,41$ & $\% 35,34$ \\
\hline Sivas & $\% 43,89$ & $\% 45,64$ & $\% 33,31$ & $\% 33,75$ & $\% 29,09$ & $\% 29,64$ \\
\hline Yozgat & $\% 44,43$ & $\% 45,75$ & $\% 34,57$ & $\% 34,63$ & $\% 28,38$ & $\% 26,52$ \\
\hline
\end{tabular}

Özellikle işletmenin üretim sisteminin planlanmasında; üretimde uygulanacak tarla işlemlerinin zamanında gerçekleştirilebilmesi için, çevre faktörlerinin de dikkate alınması ile belirlenen "uygun tarla çalışma günleri” nin bilinmesi gerekmektedir. Yani, herhangi bir üretim işleminin yapılacağı dönemde, işletmenin/yörenin toprak ve iklim özelliklerine bağlı olarak, ne kadar süreyle çalışılabileceğinin önceden tahmin edilerek bilinmesi, işletmede buna göre planlamanın yapılmasını sağlayacaktır. $\mathrm{Bu}$ ise, belirli tahmin modelleri kullanılarak belirlenebilen "çalışılabilir" tarla günlerinin, yörenin özelliklerine göre önceden belirlenmesi ile mümkün olabilir.

GÜNSAY programı kullanılarak İç Anadolu Bölgesi için çalışma yapıldığında, oluşturulan tabloların geneline bakıldığında iki farklı sonuç hemen dikkat çekmektedir.

Bunlardan ilki; toprak işleme için çalışılabilir gün oranları \%45-55 civarında iken, bakım işlemleri için bu oran \%32-42 arasında, hasat işlemlerinde ise bu oran 3038 arasında olduğu görülüyor. Bu oranlara bakıldığında İç Anadolu bölgemizdeki çiftçilerin toprak işleme işlemleri için uygun günleri daha rahat bulabilirken, hasat işlemleri için çalışılabilir gün oranları daha fazla zorlanmaktadırlar.

Diğeri ise; bu çalışmanın sonucunda çiftçinin ekim hasat dönemi arasında çalışılabilir gün sayısının son iki beş y1llık periyotlarda (1997-2002 ve 2002-2007) arttı̆̆ görülmüştür, çalışılabilir gün sayısını belirlemede dikkate aldığımız parametrelere baktığımızda, çalışılabilir günlerde ve önceki günlerde düşük yağış miktarı veya hiç yağışın olmaması, bununla birlikte sıcaklıkların da yüksek olması gerekmektedir. Bununla birlikte çalışma yapacağımız bitkilerden optimum verimi sağlayabilmek için dikkate aldığımız parametrelerin (yağış ve sıcaklık) çalışılabilir gün değerlerinin aksi olması gerekmektedir, yani bitkinin gelişmesi için bol yağış ve uygun sicaklıklar gerekmektedir ki bu şartlar sağladığında optimum verim alınabilsin. Bu veriler dikkate alındığında son iki beş yıllık periyotlar dikkate alındığında İç Anadolu'da bitkilerin gelişme dönemlerinde (bakım çalışmaları periyodu) yağış azlığının söz konusu olduğu görülmektedir ki bu da çalışılabilir gün sayısının artığı periyotlarda (son iki beş 
y1l) susuz tarım yapılan yerlerde verimde azalmalar görünmesine sebep olacaktır. Bunun yanında sulu tarım yapılan yerlerde çalışılabilir gün sayısının fazla olması, bitkinin gelişimi için gerekli suyu dışardan sağlayabileceğimiz için, çiftçinin çalışma planlamasını daha rahat yapabilmesini sağlayacaktır.

\section{Kaynaklar}

Arın S, Kayışoğlu B. 1985. Tekirdağ ilinde ayçiçeği ekiminde uygun günler olasılığının saptanması üzerinde bir araştırma. Tarımsal Mekanizasyon 9. Ulusal Kongresi Bildiri Kitabi, 378 - 384, 20-22 May1s, Adana.

Bölükoğlu H. 1982. Aksaray yöresine uygun tarım makinaları optimizasyon modeli üzerinde bir araştırma. Doçentlik tezi, Ankara Üniv. Ziraat Fakültesi Tarım Makinaları Bölümü Kütüphanesi.

Ceyhan V. 1998. Samsun ili Vezirköprü ilçesinde sığır besiciliğine yer veren işletmelerin değişken fiyatlı programlama yöntemi ile planlanması. A.Ü. Fen Bilimleri Enstitüsü, Tarım Ekonomisi Anabilim Dalı, Doktora tezi, Ankara.

Cinemre HA. 1990. Şanlıurfa (Akçakale) tarımsal üretim planlamasi. A.Ü. Fen Bilimleri Enstitüsü, Tarım Ekonomisi Anabilim Dalı, Doktora tezi, Ankara.

Çetin B. 1987. Tekirdağ ili merkez ilçesinde ayçiçeği yetiştiren tarım işletmelerinin doğrusal programlama metodu ile planlanması. A.Ü. Fen Bilimleri Enstitüsü, Tarım Ekonomisi Anabilim Dalı, Doktora tezi, Ankara.

DARGA A. 1989. Tarım işletmelerinde mekanizasyon planlamasına yönelik zaman kısıtlı model geliştirilmesi. Doktora Tezi, Çukurova Üniversitesi, Adana $238 \mathrm{~s}$.

Dellal İ. 2000. Antalya ili k1l keçisi yetiştiriciliğine yer veren tarım işletmelerinin ekonomik analizi ve planlaması. A.Ü. Fen Bilimleri Enstitüsü, Tarım Ekonomisi Anabilim Dalı, Doktora tezi, Ankara.

Demirci R. 1978. Kırşehir merkez ilçesi hububat işletmelerinde optimal işletme organizasyonları ve yeter gelirli işletme büyüklüklerinin saptanması üzerine bir araştırma. A.Ü. Fen Bilimleri Enstitüsü, Tarım Ekonomisi Anabilim Dalı, Doçentlik tezi, Ankara.

Demirci R. 1980. Orta Anadolu Bölgesi'nde çalışma dönemleri ve tarla çalışma günlerinin tespiti üzerine bir araştırma. Tarımsal araştırma dergisi, Cilt:2, Sayı:3, Ankara.

Elliot RL, Lembke WD, Hunt DR. 1977. A Simulation model for predicting available days for soil tillage. Trans of ASAE 20(1), $4-8$.

Erkuş A. 1976. Tavşanlı ilçesi şekerpancarı yetiştiren tarım işletmelerinin doğrusal programlama metodu ile planlanması. Türk Ziraat Yüksek Mühendisleri Birliği Yayımları. Yayın no: 3, Ankara

Fidan H. 1996. Kütahya merkez ilçede bünyesinde pazara yönelik süt sığırlarına yer veren tarım işletmelerinin ekonomik analizi ve planlaması. A.Ü Fen bilimleri Enstitüsü Tarım Ekonomisi Ana Bilim Dalı, Doktora Tezi, Ankara.

Fulton CV, Ayres GE, Headly ED. 1976. Expected number of day suitable for field work in Iowa. Trans. of ASAE 19 (6): 1045 1047.

Güzel E, Haktanır T. 1986. Çukurova Bölgesinde yerfıstığı hasadı için uygun gün sayılarının tahmini. Tarımsal Mekanizasyon 10. Ulusal Kongresi Bildiri Kitabı, 381 - 392, 5 -7 Mayıs, Adana.

Hetz EJ, Gold A, Reese LE. 1983. Computer prediction of suitable work days for mechanized winter wheat operation in Chili. AMA 14 (3): $62-66$.

Işık A, Sabanc1 A. 1989. Uygun tarla çalışma günlerinin bilgisayarla tahmini. Tarımsal Mekanizasyon 12. Ulusal Kongresi Bildiri Kitab1, 430 - 440, 1-2 Haziran, Tekirdağ.

Işık A, Toros H. 1992. Tarım makinaları için uygun tarla çalışma günleri modeli ve Tarsus yöresine uygulanmasi. Köy Hizmetleri Genel Müdürlüğü Tarsus Araştırma Enstitüsü Yayınları, Genel yayın no: 176, Teknik yayın no : 56, Tarsus.
İnan İH. 1977. Eskişehir Alpu ovası tarım işletmelerinde yeter gelirli işletme büyüklüğü ve organizasyonunun lineer programlama yönetimi ile saptanması. A.Ü Fen bilimleri Enstitüsü Tarım Ekonomisi Ana Bilim Dalı, Doktora Tezi, Ankara

Jones JW, Colwick RF, Threadgil ES. 1972. A simulated environmental model of temperature, evaporation, rainfall and soil moisture. Trans. of ASAE 15 (3): 366 - 372.

Kılıç O. 1997. Samsun İli Çarşamba ve Terme ilçelerinin ova köylerinde fındık üretimine yer veren tarım işletmelerinin ekonomik analizi ve findığa alternatif üretim planlarının araştırılması. A.Ü Fen bilimleri Enstitüsü Tarım Ekonomisi Ana Bilim Dalı, Doktora Tezi, Ankara.

Kıral T. 1998. Türkiye'de tarımsal iş gücü arzı. Türkiye'de tarımsal yapı ve istihdam, DİE yayınları, yayın no: 2210, Ankara.

Özçelik A. 1985. Samsun ilinde çalışma dönemleri ve tarla çalışma günlerinin tespiti üzerine bir araştırma. Ziraat Mühendisliği dergisi sayı:174, Ankara.

Özçelik A. 1993. Erzincan ili merkez ilçesi tarım işletmelerinde iş gücü varlığı ve kullanım durumu. A.Ü Fen bilimleri Enstitüsü Tarım Ekonomisi Ana Bilim Dalı, Yüksek Lisans Tezi, Ankara.

Parsons SA, Doster DH. 1982. days suitable for fieldwork in Indiana. ASAE Paper no:82 - 1523, ASAE, St Joseph. MI49085.

Rosenberg SE, Rotz CA, Black JR, Muhtar H. 1982. Prediction of suitable days fieldwok. ASAE paper no : 821032. ASAE, St Joseph. MI-49085.

Selek B, Aksu H. 2020 Water resources potential of Turkey. In: Harmancioglu N., Altinbilek D. (eds) Water Resources of Turkey. World Water Resources, vol 2. Springer, Cham.

Serin E. 1989. Sincan ilçesinde şeker pancarı tarımına yer veren işletmelin optimal iletme organizasyonlarının tespiti. A.Ü Fen bilimleri Enstitüsü Tarım Ekonomisi Ana Bilim Dalı, Doktora Tezi, Ankara

Sındır KO, Evcim Ü. 1992. Çalışılabilir gün sayılarının toprak nemi modeli ile bilgisayar desteğinde tahmini. Tarımsal Mekanizasyon 14. Ulusal Kongresi Bildiri Kitabı, 474 - 483, 14-16 Ekim, Samsun.

Tatlidil F. 1987. Nazilli ilçesinde bünyesinde pamuk üretimine yer veren tarım işletmesi optimal işletme organizasyonunun tespiti üzerine bir araştırma. A.Ü Fen bilimleri Enstitüsü Tarım Ekonomisi Ana Bilim Dalı, Yüksek lisans Tezi, Ankara.

Tatlıdil F. 1992. Konya ili sulu ve kuru koşullardaki tarım işletmelerinde iş gücü, döner sermaye ve traktör güçlerine göre optimal işletme büyüklüğüün tespiti. A.Ü Fen bilimleri Enstitüsü Tarım Ekonomisi Ana Bilim Dalı, Doktora Tezi, Ankara.

Toros H, Işık A. 1994. Tarla çalışılabilir gün sayıları tahmin modeli Tarsus yöresi sonuçlarının gerçekleşen değerlerle karşılaştırılması. T.C. Başbakanlık Köy Hizmetleri Genel Müdürlüğü Tarsus Araştırma Enstitüsü Müdürlüğü Yayınları, yayın no: 190 , rapor seri no: 124 , Tarsus

Tulu MY, Holtman JB, Fridley RB, Parsons SD, 1974. Timelines cost and available working days - shelled corn. Trans. of the ASAE 17 (5): 798 - 800.

Vatandaş M. 1987. Ankara koşularında sulanabilir 10 hektarlık bir tarım işletmesi için en uygun mekanizasyon modelinin tespiti. A.Ü Fen bilimleri Enstitüsü Tarımsal mekanizasyon Ana Bilim Dalı, Yüksek Lisans Tezi, Ankara

Von Bargen K, Meng J, Schroeder MA. 1986. Field working time for agricultural equipment management in Nebraska. ASAE paper no: 86 - 1024, USA.

Williams DL. 1980. Fieldwork days in Iowa estimated number suitable. Machinary Management Series, PM - 695, Cooperative Extension Servise, Iowa State University, Aems, Iowa - 50011, USA. 